\title{
Survey and BIM for Energy Upgrading. Two Case Study
}

\author{
Marco Filippucci \\ Fabio Bianconi \\ Michela Meschini
}

Abstract

This research aims to deal with the theme of the survey applied to the BIM methodology in cultural heritage; in particular on those buildings that, although from different periods and construction technologies, require energy requalification. The study focuses on two cases in Umbria: Borgo Lizori, a characteristic historical settlement located along the Assisi-Spoleto olive grove, and the Palazzetto dello Sport in Bastia Umbra, a post-modern building designed by arch. Leoncilli Massi.

Keywords

cultural heritage, energy efficiency, BIM.
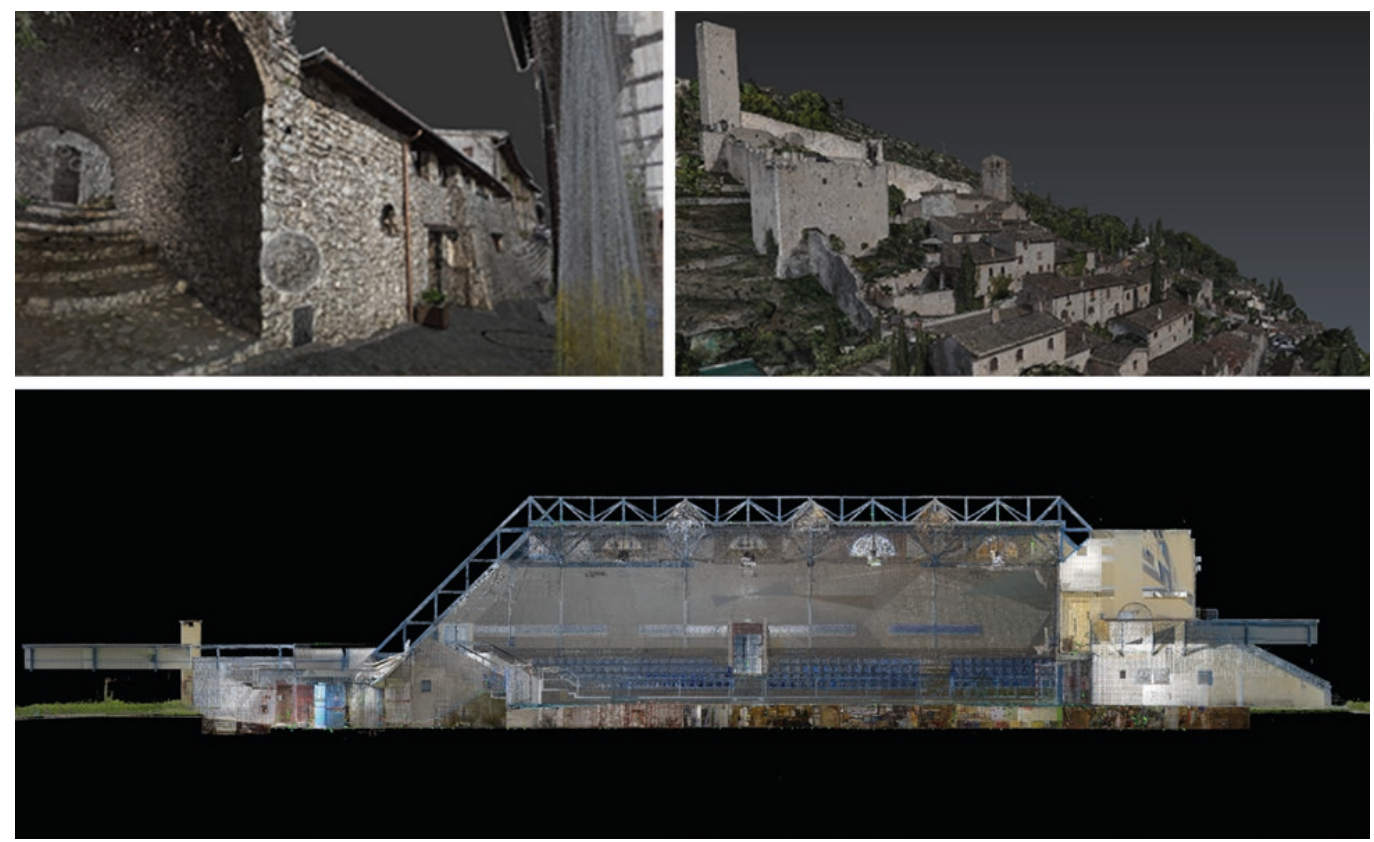


\section{Introduction}

In recent years there has been a steady increase in demand for the rehabilitation of the existing building stock, both historic and more recent. Intervention on the built heritage has to face increasing challenges and opportunities, such as the recent tax reliefs issued by the government; the resulting expectations are related to sustainability, energy saving, as well as the availability of new materials and continuous technological innovations. In this context, it is essential to understand the building, its genesis and its technological characteristics. Particular attention must be paid during the survey phase which, in the most complex cases, is facilitated by the use of drones or laser scanners, which make it possible to obtain a digital clone in a short time but with high accuracy. The point cloud obtained in this way is then imported into the BIM environment; from here it is possible to reconstruct the geometric elements, classified into hierarchical structures, and explored with different levels of detail. This procedure was carried out in the two cases that will be presented here; they are two profoundly different cases, but from which emerges as the lowest common denominator the need for energy regeneration, the point of convergence of a methodological research path that starts from the survey and projects itself to integrate the multiple information in the BIM environment.

\section{The Case of Borgo Lizori}

Lizori Burg, a settlement located on the hill between Foligno and Spoleto in the city of Campello sul Clitunno (PG) and a UNESCO World Heritage Site, represents the first case study. The very first inhabitants of the area were the Umbrian, an Italic people from Central and Eastern Europe who came to the peninsula around I000 BC. Subsequently, the place will take the name of the castle of Pissignano, derived from the ancient Pissinianum, or swimming pool of Giano. The first nucleus developed in Roman times along the Flaminia, while later the hilly one was formed, where a small Benedictine community was established, presumably around the eleventh century. Between the eleventh and twelfth centuries, the monks erected a wall around the inhabited center, which therefore took the name of San Benedetto Burg. Over the centuries, the burg was often disputed due to its privileged strategic position. The recovery of the Burg, which took place from the mid-seventies, on the one hand gave new life to a place that was abandoned, on the other it was an opportunity for the application of good practices: the local materials were recovered, put in place with traditional construction techniques, so much so that they were shown at the IUA World Congress in 2005.

Its triangular shape has the summit upstream, with towers originally arranged at the corners and on the two sides inclined in an intermediate position. The urban layout is quite characteristic: it has a compact terraced layout of buildings with parallel lots and a trend that sets itself on con-

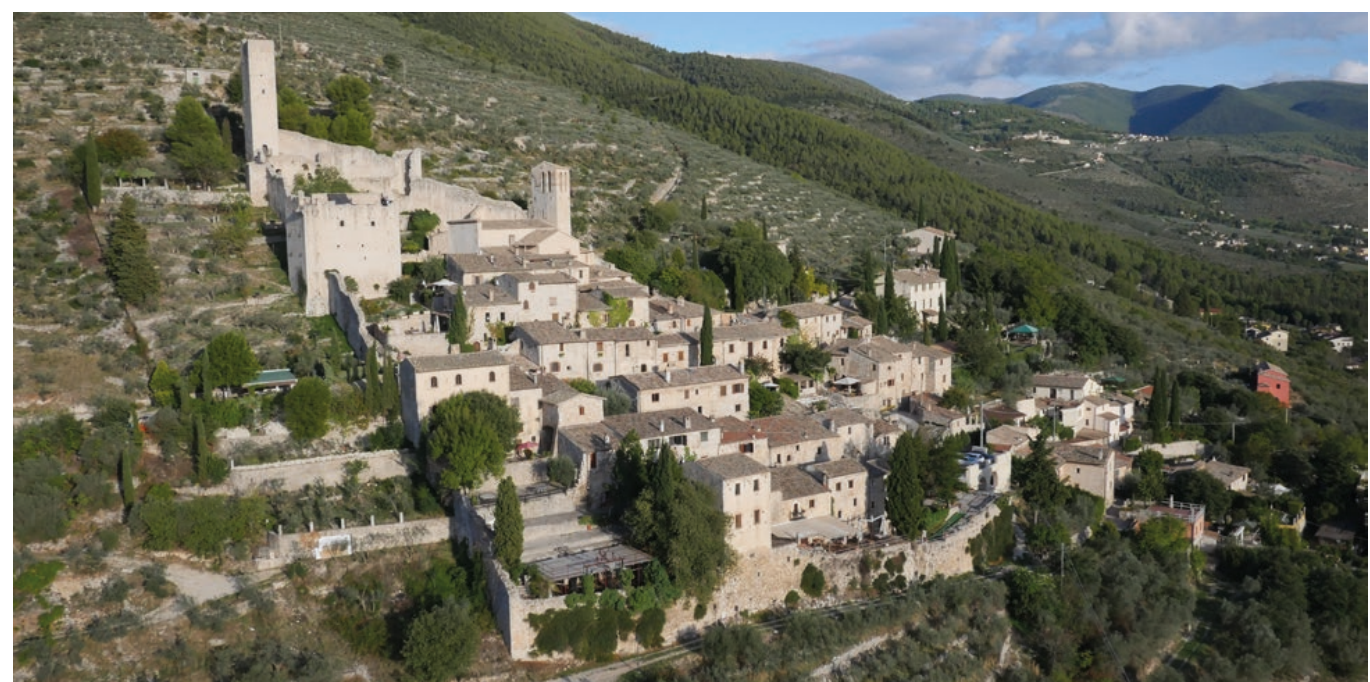


tour lines, rapidly degrading along the slope. The village is in a perfect state of conservation and presents architectural forms in relation to nature, as well as purely artistic decorative elements. As preliminary survey, a model was developed through aerial-photo modeling techniques, a technique that offers considerable advantages for dense patterns, such as the case study. It was possible to survey the whole village, and represent the roof shape in detail using a professional EVO 4HSE drone. The flying and the image acquisition phase lasted 8 hours. In this phase more than 20 marker were positioned on the ground to facilitate the aero-triangulation and to limit the cameras orientation error. The camera used for this phase is a LUMIX DMC-GH4 digital mirrorless with a single lens, on a Panasonic I4- 8 mm optic. The software used for photo modelling is ContextCapture (Bentley).

Once concluded the input and marker georeferencing phase, it is possible to move to the aerotriangulation phase, where among the options it is possible to set: density of key points, choice of methods of similar photos and adjustments of focal distortions. When completed the cameras alignment phase, it was the time to produce the dense cloud choosing points' density, texture quality and the mesh parameters. Subsequently, the survey data were merged and geo-oriented through the 3Dreshaper software, thanks to which it was possible to extrapolate further data such as the land digital model and the built environment shape to hierarchize the point cloud.

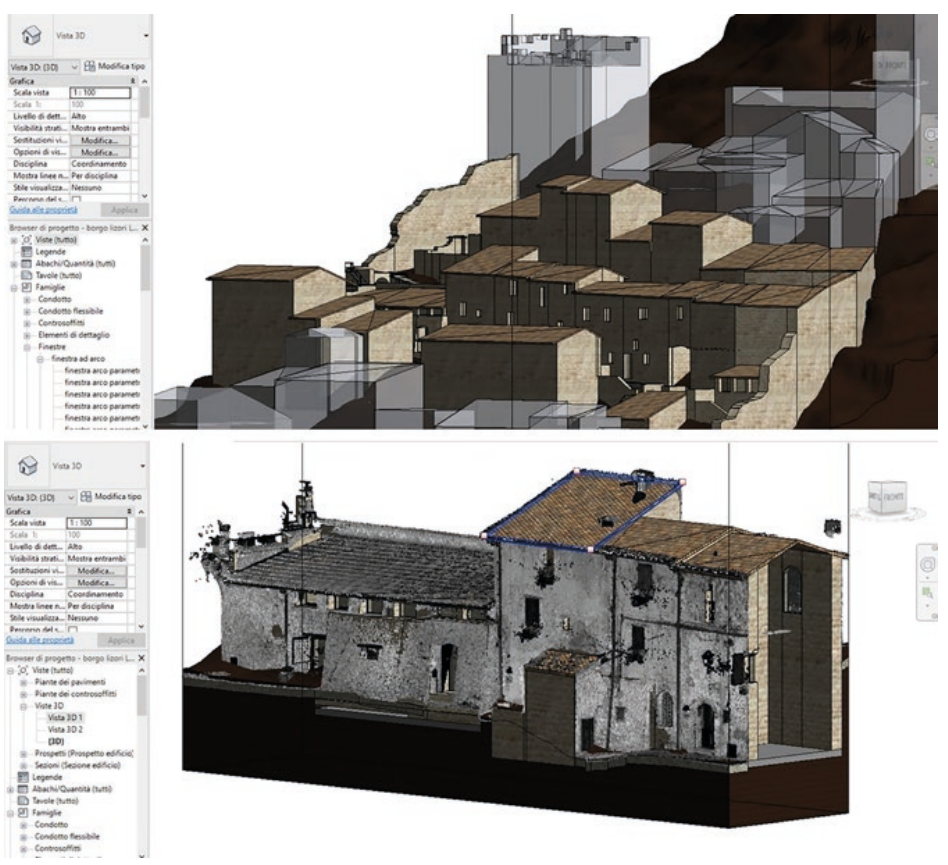

By selecting the most widely used Autodesk BIM Revit software as a reference tool, operationally it was necessary to index the geo-referred data through the Recap software to ensure direct management in the identified digital environment. From the cloud of points is possible to move on to the interpretation of the shapes detected through the modelling of geometries. This are differently detailed in terms of scalar levels of detail, addressing the multiple issues related to the definition in parametric informational environment of singular and peculiar elements, such as those met in historical contexts like the case study.

Using 3DReshaper software, it was possible to export the BIM Revit model in FBX format and overlap it to the cloud of points from the laser scan, to calculate the variance, intended as the distance between homologue points of the BIM model and the relief.The obtained mistake is the sum of different factors and the average values are in the order of $5 \mathrm{~cm}$, an acceptable value connected to the vernacular character of urban space and the possible needs of a representative approximation.

The use of this platform has allowed the model to add a series of details relating to the structure of the individual buildings, ranging from the stratigraphy of the wall facings to 
that of the roofs, passing through the types of heating system. This implementation of data has made it possible to carry out a series of analyzes on the current state of affairs from an energy point of view, allowing the development of a series of design strategies for the redevelopment of the individual element and, consequently, of the entire burg. In particular, the building envelope was studied, including both the external walls and the roof; a project was carried out for the inclusion of home automation, and the lighting was studied, including a study of both the internal and external environments.

\section{The Case of the Sports Hall in Bastia Umbra}

The Sport Hall in Bastia Umbra was designed by the architect Leoncilli Massi in the 1970s as a covered market for the S. Lucia area; later, following the granting of funds by CONI, the use of the building was changed to sport hall in what is now the Giontella area.

The building has an atypical truncated pyramid shape, with a rectangular base rather than a square one, and a basement that was originally intended to contain boxes for the open-air market. But if the pyramid works by gravity, Leoncilli Massi reverses the logic and inserts an exoskeleton, a characteristic element of the entire project. The structure recalls the themes of post-modern architecture, such as the colours chosen or rather the arch-window; and again, the fragmentary nature found in every corner of the building, where stairways, exits and entrances are inserted. Lastly, the misalignment, with the basement creating an 'L' on the east side. Almostforty years have passed since its inauguration on 16 November 1983, and the Sport Hall, although it has been selected by MiBAC as one of the most important works of contemporary architecture, presents a number of critical issues due to the technologies used at the time, such as infiltrations and thermal bridges, as well as more'recent' problems such as parkour and graffiti. The survey was carried out using a laser scanner with a spherical camera; in this case, through the software installed on the mobile device, it is possible to see in real time the cloud of points that is gradually forming, as well as the positioning of the instrumentation. (fig. 4) The model that is created is geo-referenced. For simplicity's sake, the operations for importing it into a BIM environment, already seen in the previous paragraph, are omitted. This led to a series of hypotheses which, on the one hand, resolve the technological difficulties, aim at energy requalification and, finally, restore the contemporary architecture. In particular, solutions were studied to eliminate water infiltration, redo the window and door frames and study thermal insulation. Finally, a proposal for a new external skin that does not distort the work but at the same time makes it contemporary.

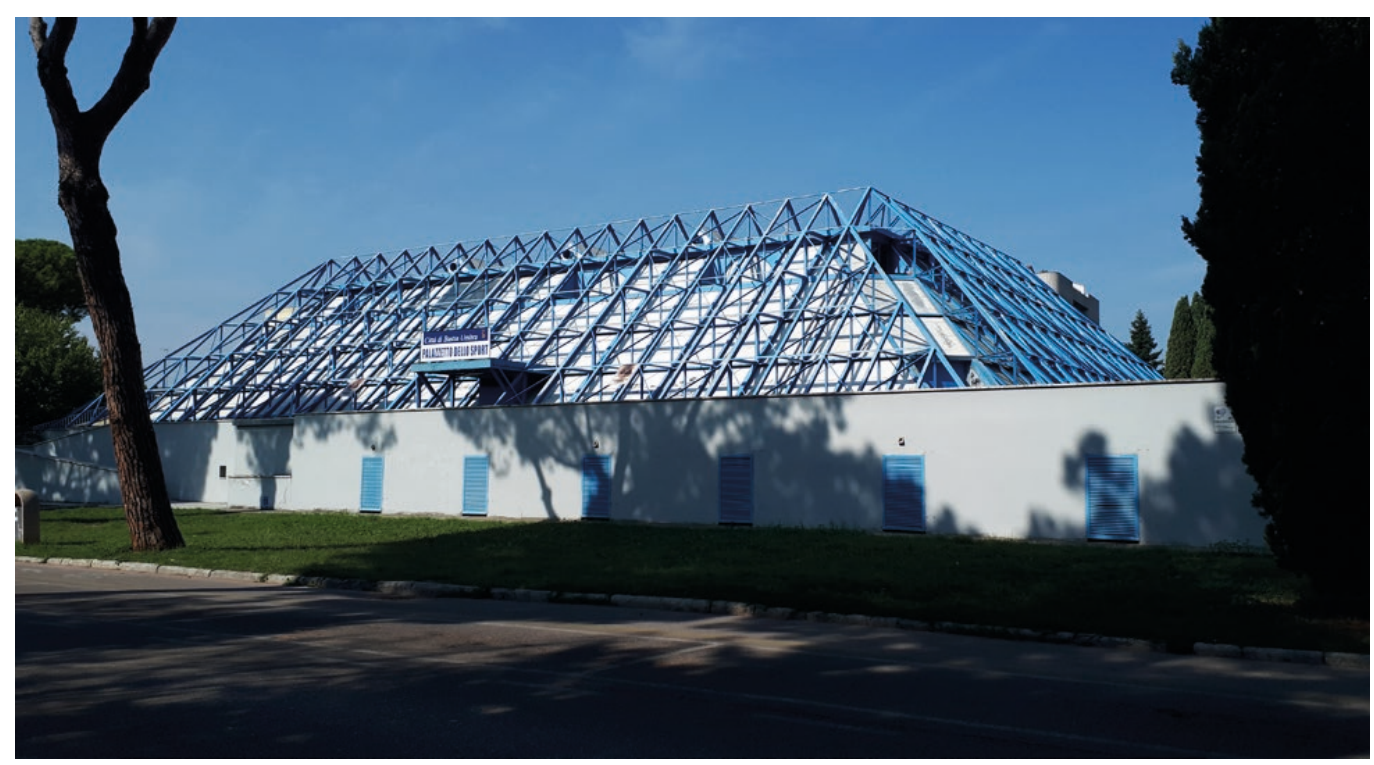



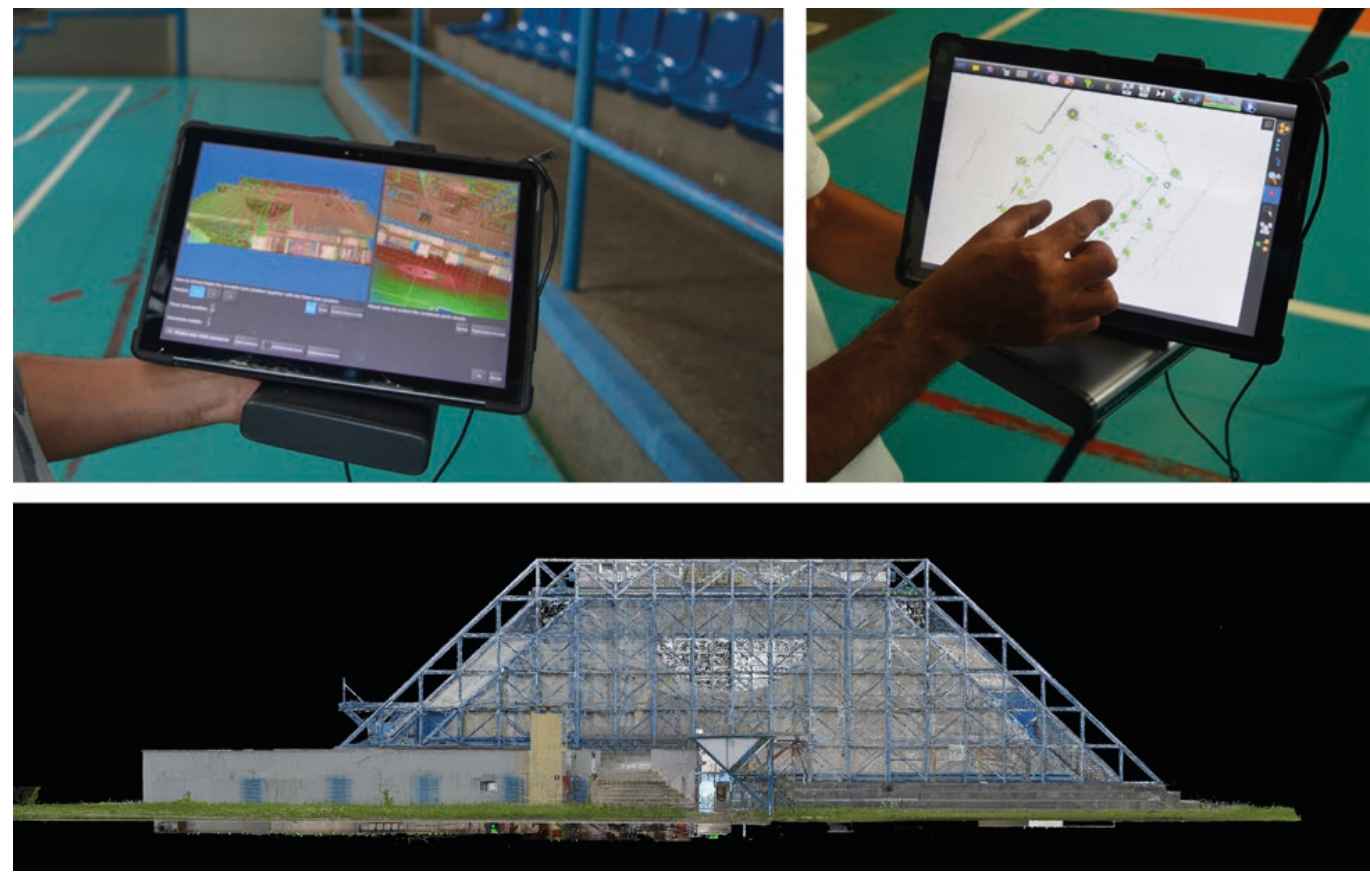

\section{Conclusions}

This contribution aims to compare two case studies, profoundly different, but which have in common the need for energy regeneration. Starting from the point cloud, necessary in these cases where the survey operations present objective difficulties, a first step was the implementation in a BIM environment; the research will be perfected with immersive experiences in an Al/AR environment, which will allow a further enhancement of the cultural heritage. Through the case studies, the research aims to highlight the centrality of a methodological workflow in its ability to manage and interpret data, which becomes fundamental for the knowledge and enhancement of the richness of our heritage of historical and environmental interest.

\section{References}

Argan Giulio Carlo (1965). La cultura Progetto e Destino. Milano: II Saggiatore.

Bianconi Fabio, Filippucci Marco,Amoruso Giuseppe, Bertinelli Mattia (2019). From the integrated survey of historic settlements to the pattern book within the BIM. In International Archives of the Photogrammetry, Remote Sensing and Spatial Information Sciences XLII-2/W9, pp. I35- |42

Burattini Chiara, Nardecchia Fabio, Bisegna Fabio, Cellucci Lucia, Gugliermetti Franco, Vollaro Andrea D.L., Salata Ferdinando, Golasi lacopo (20 I5). Methodological Approach to the Energy Analysis of Unconstrained Historical Buildings. In Sustainability, 7 (8), pp. $10428-10444$.

Calzolari Marta (2016). Prestazione Energetica delle Architetture Storiche: Sfide e Soluzioni. Analisi dei Metodi di Calcolo per la Definizione del Comportamento Energetico. Milano: FrancoAngeli.

Cicerchia Annalisa (2009). Risorse Culturali e Turismo Sostenibile. Elementi di Pianificazione Strategica. Milano: FrancoAngeli.

Coletta Tiziana (2008). II Paesaggio Dei Centri Abbandonati. In Territorio della ricerca su insediamenti e ambiente, 2, pp. I I 7- I 26. Mumford Lewis ( $196 \mathrm{I}$ ). The City in History: Its Origins, Its Transformations, and Its Prospects. New York: Harcourt Brace Jovanovich. Piano Renzo (20 I5). Renzo Piano: Rammendo e Rigenerazione Urbana per II Nuovo Rinascimento. IngenioWeb.

Volpe Giuliano (20 I6). Un Patrimonio Italiano: Beni Culturali, Paesaggio e Cittadini. Milano: UTET.

\section{Authors}

Marco Filippucci, Dept. of Civil and Environmental Engineering, University of Perugia, marco.filippucci@unipg.it Fabio Bianconi, Dept. of Civil and Environmental Engineering, University of Perugia, fabio.bianconi@unipg.it

Michela Meschini, Dept. of Civil and Environmental Engineering, University of Perugia, michela.meschini@yahoo.com 
